\title{
THREE-DIMENSIONAL SUBSIDENCE MONITORING OF RECLAMATION AREA BASED ON TS-INSAR TECHNOLOGY
}

\author{
Chao Ren ${ }^{1,2}$, Xianjian Shi ${ }^{1}$, Lv Zhou ${ }^{1,4}, *$, Yuanlin Huang ${ }^{3}$, Yueji Liang ${ }^{1,2}$, Zilin hhu $^{1}$, Xianguang Li $^{1}$ \\ ${ }^{1}$ College of Geomatics and Geoinformation, Guilin University of Technology, Guilin China - (shixianjian@glut.edu.cn, \\ zhoulv_whu@163.com, lyjayq@glut.edu.cn, zhuzilin@glut.edu.cn,2761419719@qq.com) \\ ${ }^{2}$ Guangxi Key Laboratory of Spatial Information and Geomatics, Guilin China - renchao@glut.edu.cn \\ ${ }^{3}$ College of Resources and Environment, Beibu Gulf University, Qinzhou China - huangyuanlin@yeah.net \\ ${ }^{4}$ Key Laboratory of Geospace Environment and Geodesy, Ministry of Education, Wuhan University, Wuhan China
}

KEY WORDS: TS-InSAR, Three-dimensional Subsidence Monitoring, Reclamation Area, Time Series Analysis, Spatial-Temporal
Changes

\section{ABSTRACT:}

This study used the Time Series Interferometric Synthetic Aperture Radar (TS-InSAR) technology and the ENVISAT ASAR dataset obtained between 2007 and 2010 and the Sentinel-1A dataset from 2017 to 2019 to determine the subsidence in the Shenzhen reclamation area, and used ASTER GDEM V2 to remove the phase jump caused by spectral decorrelation between bursts. Based on the time series of land subsidence of the reclamation area, a three-dimensional subsidence model of the reclamation area was established. By comparing and analyzing the subsidence results of two sets of satellite time series in the reclamation area, the temporal and spatial evolution of land subsidence and the cause of land subsidence in the reclamation area were analyzed. The results show that the test results of time series ENVISAT ASAR and Sentinel-1A have good continuity in subsidence spatialtemporal variation: From 2007 to 2010, the land subsidence in most areas of Shenzhen reclamation area is relatively stable, and the area where subsidence occurs is mainly distributed in Baoan District, the maximum subsidence rate in Baoan District is -23.12 $\mathrm{mm} /$ year. From 2017 to 2019, land subsidence in the reclamation area showed a tendency to spread and spread from west to east. The subsidence characteristics of Nanshan District are the most obvious, and the maximum subsidence rate is $-17.52 \mathrm{~mm} / \mathrm{year}$.

\section{INTRODUCTION}

With the continuous expansion of coastal cities and the rapid growth of land demand, the problem of scarcity of land resources have become increasingly prominent. In addition, to strengthening the development of the remaining construction land and improving the level of land conservation and intensive use, reclamation has become one of the important ways to solve the shortage of land resources in coastal areas (Xu et al, 2016). As the first special economic zone established by China's reform and opening up, Shenzhen has expanded over $80 \mathrm{~km}^{2}$ of land through reclamation in the past few decades (Du et al, 2017). However, there are more silt in the reclamation area, the geology is weak, and the nature of the formation filler is different. With the continuous increase of land load in the reclamation area and the gradual consolidation of the land, it is easy to cause land subsidence, which will affect urban development and people's lives and property (Liu et al, 2018). Therefore, it is of great significance to carry out subsidence monitoring and study the subsidence law of the Shenzhen reclamation area.

The traditional land subsidence monitoring methods are GPS measurement and leveling surveying. However, the traditional measurement method has the disadvantages of long cycle, large workload, high cost, not easy to save the measurement points and unable to achieve large-area detailed measurement (Guo et al, 2016). Differential Interferometric Synthetic Aperture Radar (D-InSAR) technology has the advantages of high precision, wide range, all-weather, all-day time, and can overcome the shortcomings of traditional GPS measurement and leveling, providing a new method for land subsidence monitoring (Zhou et al, 2018). However, D-InSAR is susceptible to temporal decorrelation and atmospheric delay interference, and is generally used for deformation monitoring in short time intervals. Therefore, D-InSAR is generally not used for highprecision long-term time series land monitoring (Zhou et al, 2017). Domestic and foreign scholars have proposed TSInSARtechnology based on D-InSAR. At present, TS-InSAR technology has been successfully applied to land deformation monitoring (Zhang et al, 2018, Chen et al, 2018, Zhang et al, 2019, Wang et al, 2 019). Tang et al (2018) used 75 ENVISAT ASAR images collected from August 2003 to September 2010 and 33 TerraSAR-X scenes from March 2009 to March 2010, based on TS-interferometric SAR analysis, the land subsidence of the entire Taiyuan Basin area is investigated. And compared with GPS data, the reasons for the land subsidence in Taiyuan Basin were analyzed and discussed. Wang et al (2018) used the ENVISAT ASAR dataset collected from 2003 to 2010 and the TerraSAR-X dataset collected from 2010 to 2016, based on TSInSAR technology, the land deformation law of Akutan volcano from 2003 to 2016 was analyzed and discussed. Shi et al (2019) used 16 ALOS PALSAR data sets collected from January 1, 2007 to February 27, 2011, based on TS-InSAR technology, the subsidence law of Wink sinkholes is analyzed and discussed.

This study used TS-InSAR technology and the ENVISAT ASAR (20 scenes acquired from 2007-02-28 to 2010-02-17) dataset and the Sentinel-1A (20 scenes acquired from 2017-0815 to 2019-03-14) dataset to determine the subsidence in the Shenzhen reclamation area, and used ASTER GDEM V2 to remove the phase jump caused by spectral decorrelation between bursts. Based on the time series of land subsidence of the reclamation area, a three-dimensional subsidence model of

\footnotetext{
* Corresponding author: Lv Zhou; E-mail: zhoulv_whu@163.com
} 
the reclamation area was established. By comparing and analyzing the subsidence results of two sets of satellite time series in the reclamation area, the temporal and spatial evolution of land subsidence and the cause of land subsidence in the reclamation area were analyzed.

\section{STUDY AREA AND DATA SET}

The Shenzhen Reclamation Area, consisting of Shenzhen Airport, Baoan Center, Qianhai Bay and Shenzhen Bay, is located in the southwest of Shenzhen, on the east bank of the Pearl River Estuary. The reclamation area is separated from Hong Kong by water and is the key planning area of Shenzhen. According to the data released by the Shenzhen Geological Bureau, Shenzhen has expanded more than 80 square kilometers of land here by reclamation in the past few decades. An overview of the Shenzhen reclamation area is shown in Figure 1. This study used the TS-InSAR technology and the ENVISAT ASAR dataset obtained between 2007 and 2010 and the Sentinel-1A dataset from 2017 to 2019 to determine the subsidence in the Shenzhen reclamation area. The basic parameters of the two satellites are shown in Table 1, and the image coverage is shown in Figure 2.

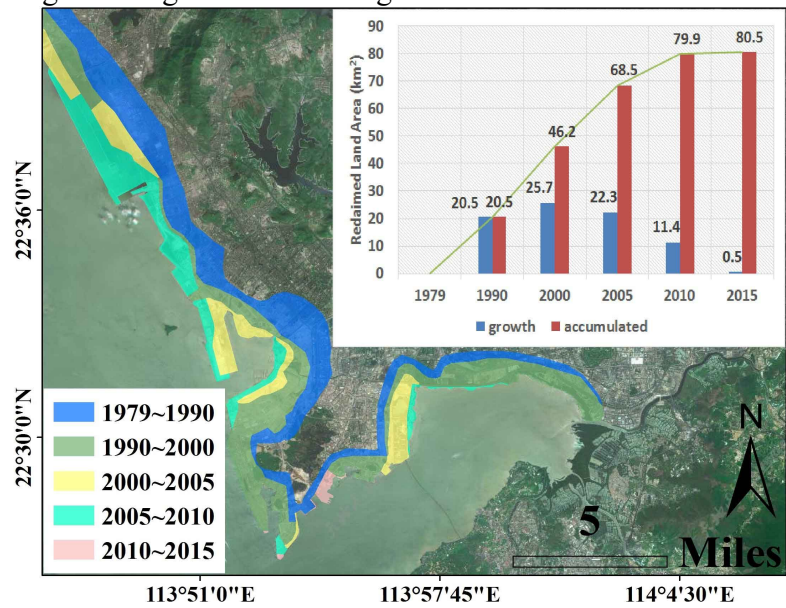

Figure 1. Overview of Shenzhen reclamation area

Table 1. Basic parameters of the satellite

\begin{tabular}{|c|c|c|}
\hline Parameters & \multicolumn{2}{|c|}{ Description } \\
\hline Type & ENVISAT ASAR & Sentinel-1A IW SLC \\
\hline Orbit direction & Ascending & Ascending \\
\hline $\begin{array}{c}\text { Incidence } \\
\text { Angle }\end{array}$ & $25^{\circ}$ & $44^{\circ}$ \\
\hline Band & $\mathrm{C}$ & $\mathrm{C}$ \\
\hline Polarization & $\mathrm{VV}$ & $\mathrm{VV}$ \\
\hline Number of data & 20 & 20 \\
\hline Time & $20070228 \sim 2010021$ & $20170815 \sim 2019031$ \\
& 7 & 4 \\
\hline
\end{tabular}

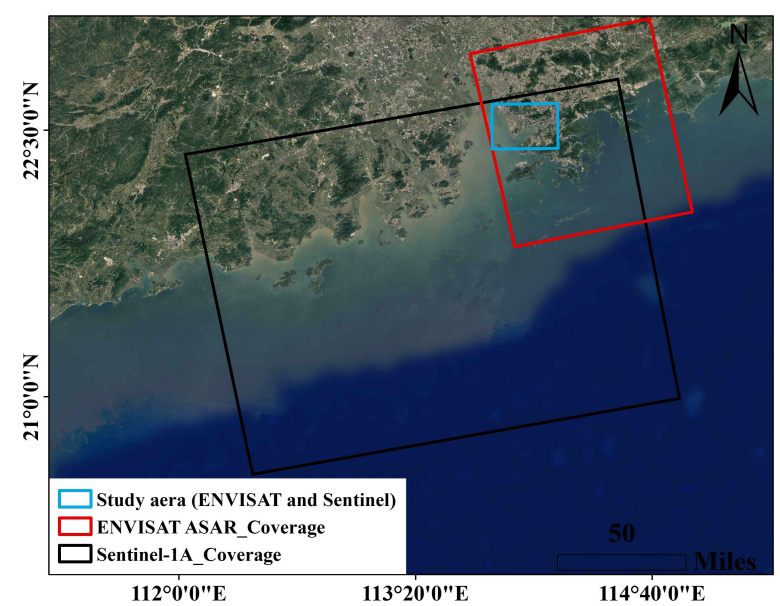

Figure 2. Satellite data range

\section{INVERSION PRINCIPLE OF LAND SUBSIDENCE}

The first step in the inversion of land subsidence in the InSAR reclamation area is to use the SAR imagery of the study area to reduce the effects of de-correlation and orbital errors by composing time-space baseline interferometric pairs. The 20 ENVISAT SAR data for 2007-2010 constitute 19 sets of interferometric pairs. The 20 Sentinel-1A data for 20172019 constitute 19 sets of interferometric pairs. Figure 3 shows the spatiotemporal baseline distribution of ENVISAR ASAR and Sentinel-1A IW SLC SAR.
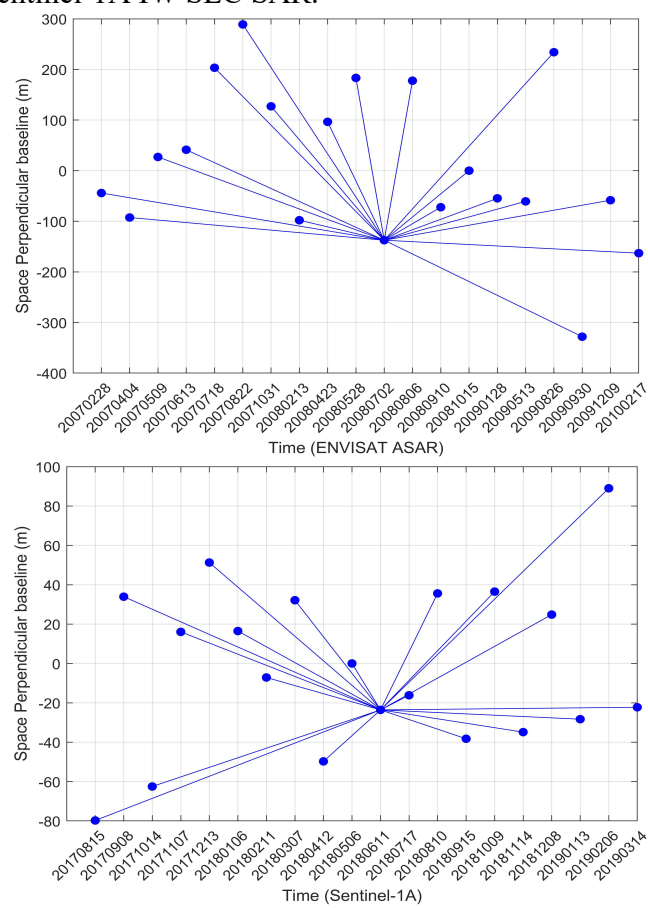

Figure 3. The spatio-temporal baseline distribution of ENVISAR ASAR and Sentinel-1A.

After constructing the spatio-temporal baseline interferometric pair, begin to model the phase slope of each pixel in the interferogram.

$$
\begin{array}{r}
\varphi(\mathrm{x}, \mathrm{y})_{\text {ramp }}=a_{0}+a_{1} \cdot x+a_{2} \cdot x^{2}+a_{3} \cdot x \cdot y \\
+a_{4} \cdot y+a_{5} \cdot y^{2}+a_{6} \cdot y+\varepsilon(\mathrm{x}, \mathrm{y})
\end{array}
$$


in which $\mathrm{x}$ is the horizontal axis coordinate orientation of the pixel; $y$ is the vertical axis coordinate orientation; $h$ represents elevation value; $a_{i}$ is estimated parameter; $\varphi(\mathrm{x}, \mathrm{y})_{\text {ramp }}$ is the analog phase ramp; $\varepsilon(\mathrm{x}, \mathrm{y})$ represents random phase error.

By modeling the phase slope of each pixel and generating an interferogram, after identifying PS and DS, the formula of the phase difference between two adjacent points $\mathrm{x}$ and $\mathrm{y}$ on the $\mathrm{k}$ th interferogram is as follows.

$$
\begin{aligned}
& \Delta \varphi_{\bmod e l}=\frac{4 \pi}{\lambda} \cdot T^{k} \cdot \Delta v(\mathrm{x}, \mathrm{y}) \\
& +\frac{4 \pi}{\lambda R \sin \theta} \cdot B_{\perp}^{k} \cdot \Delta \varepsilon(\mathrm{x}, \mathrm{y})
\end{aligned}
$$

in which $\Delta \varepsilon$ is the elevation error of two adjacent pixel on the interferogram; $\Delta v$ is the variation of the deformation rate of pixels at two adjacent points; $\theta$ is the incident angle; $R$ represents tilt range; $B_{\perp}^{k}$ represents normal baseline; $T^{k}$ is the time baseline. The elevation error and the deformation rate of the pixels of two adjacent points on the interferogram can be obtained by the following formula.

$$
\varsigma=\left|\frac{1}{N} \sum_{k=1}^{N} \exp \left(\mathrm{j} \times\left(\Delta \varphi_{\text {phase }}^{k}-\Delta \varphi_{\bmod e l}^{k}\right)\right)\right|
$$

in which $\mathrm{N}$ represents the total number of interferograms; $\Delta \varphi_{\text {phase }}^{k}$ represents the differential phase of two points on the kth interferogram. The maximum value of $\Delta \varphi_{\text {phase }}^{k}$ indicates temporal coherence.

After maximizing edge processing, quality detection is performed to filter out point targets below a certain time coherence threshold (The coherence threshold of this paper is set to 0.75 ). Finally, using the acquired deformation point target, the land three-dimensional deformation model is constructed by interpolation.

\section{RESULTS AND ANALYSIS}

\subsection{Land Deformation Results of Shenzhen Reclamation Area}

Figure 4 shows the deformation results of the Shenzhen reclamation area obtained using TS-InSAR and ENVISAT ASAR. It can be seen from Figure 4 that during the period from 2007 to 2010, the land deformation rate of the Shenzhen reclamation area ranged from -17.53 to $31.44 \mathrm{~mm} /$ year, and the subsidence area was mainly distributed in Baoan District. The maximum subsidence rate (point P1) in Baoan District is -23.12 $\mathrm{mm} / \mathrm{year}$, and the land subsidence in other areas outside the Baoan area is relatively small, and no areas with significant subsidence are found. The deformation rate histogram of the Shenzhen reclamation from 2007 to 2010 shows that the land deformation rate is mainly concentrated at -5 to $5 \mathrm{~mm} / \mathrm{year}$, and the distribution of deformation rate is relatively concentrated.

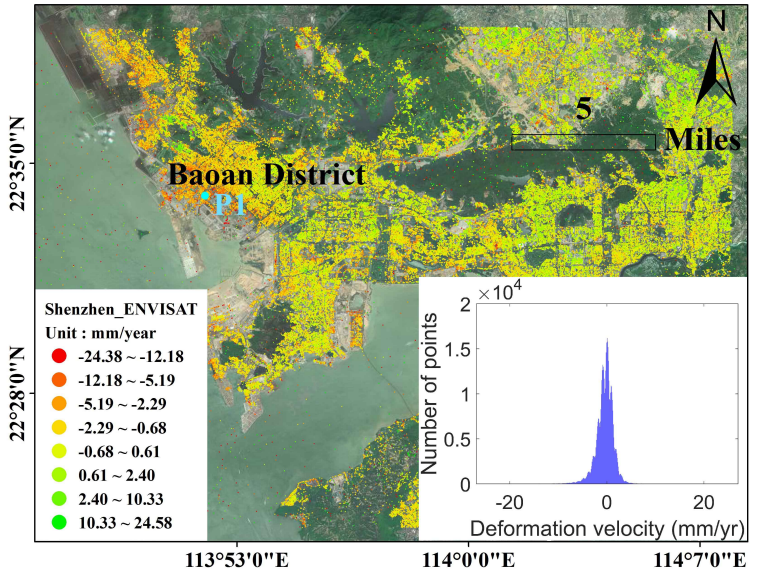

Figure 4. ENVISAT ASAR deformation results

Figure 5 shows the deformation results of the Shenzhen reclamation area obtained using Sentinel-1A. It can be seen from Fig. 5 that the land subsidence in the reclamation area from 2017 to 2019 shows a trend of spreading and spreading from west to east. The subsidence characteristics of Nanshan District are the most obvious, and the maximum sedimentation rate (point P2) is $-17.52 \mathrm{~mm} /$ year. The deformation rate histogram of the Shenzhen reclamation from 2017 to 2019 shows that the land deformation rate is mainly concentrated at $10 \sim 15 \mathrm{~mm} /$ year, and the deformation difference is large.

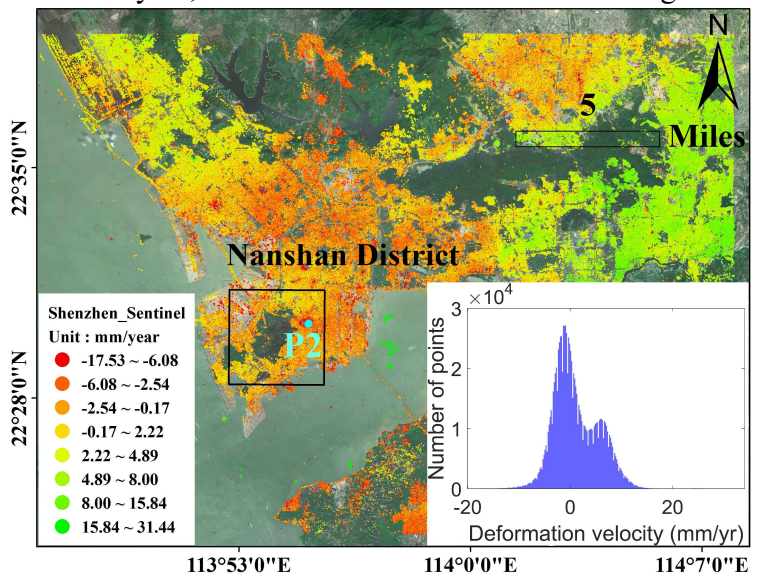

Figure 5. Sentinel-1A deformation results

Select and enlarge the P1 area from Figure 4 (the base map is the remote sensing image taken on March 4, 2008), select and enlarge the P2 area from Figure 5 (the base map is the remote sensing image taken on December 26, 2018), and select three point targets with larger subsidence values, respectively. Then generate a cumulative deformation map of the point target, as shown in Figure 6. It can be found that from 2007 to 2010, the largest cumulative subsidence (point P1) in Baoan District reached $-67.30 \mathrm{~mm}$, and the subsidence points were mostly distributed around the residential buildings. It is speculated that the increase in land construction load and the excessive concentration of personnel activities may be the cause of subsidence in the area. From 2017 to 2019, the maximum subsidence value of Nanshan District is $-14.44 \mathrm{~mm}$, and the subsidence points are mostly distributed along the road. It is speculated that the construction of roads and the frequent loading of urban rail transit networks are the main causes of subsidence in the region. 

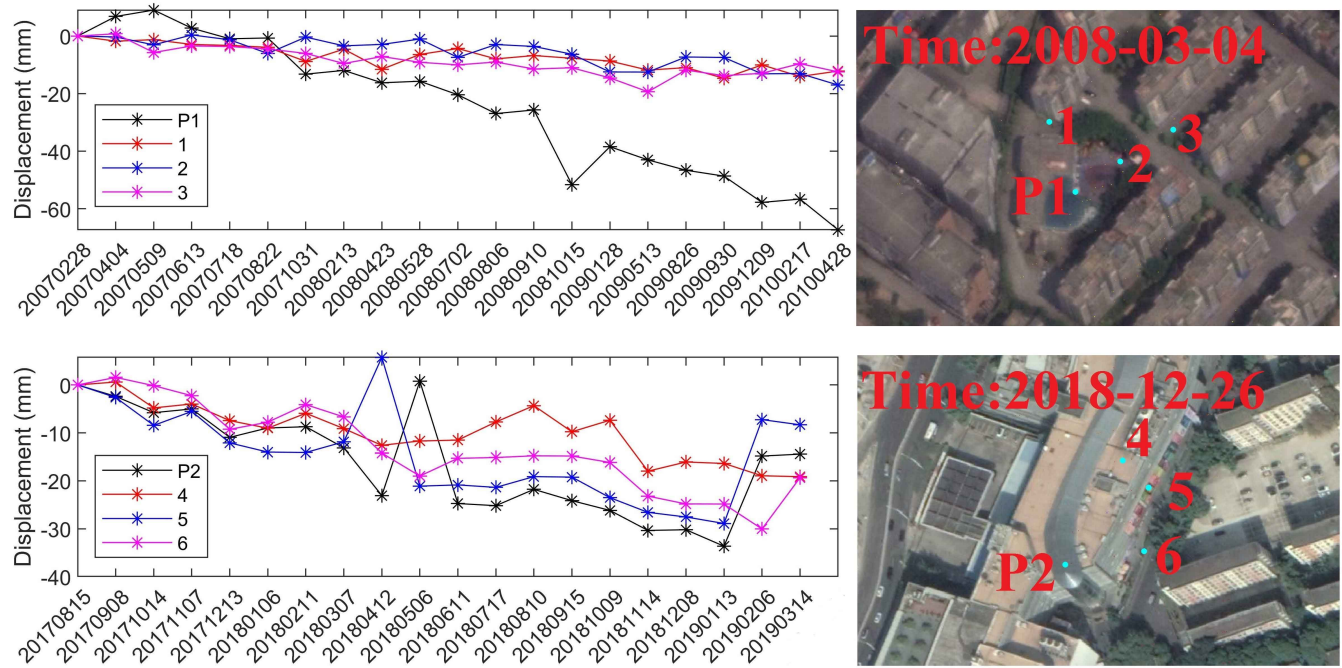

Figure 6. Cumulative deformation value of the target point

\subsection{Three-dimensional Subsidence Monitoring Analysis}

Based on TS-InSAR and ENVISAT, 479767 point targets were obtained. Using the deformation point target obtained above, a three-dimensional deformation model of the land is constructed by linear interpolation. Figure 7 shows the three-dimensional deformation model of ENVISAT.

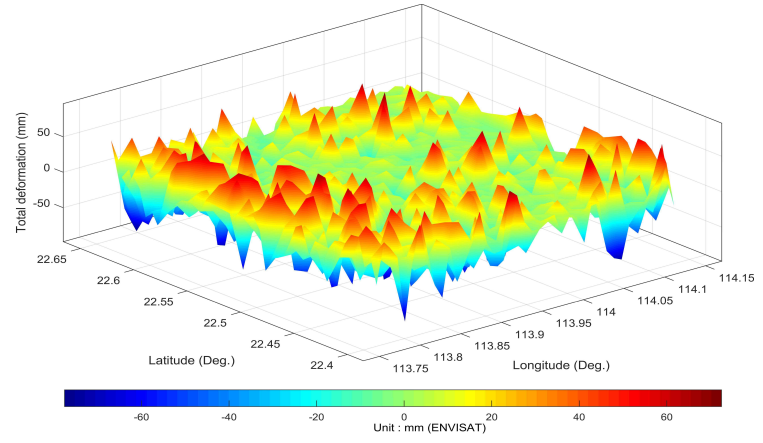

Figure 7. 3D deformation model of ENVISAT ASAR

Similarly, for the 1,048575 point targets obtained using Sentinel-1A, a three-dimensional deformation model of the land was constructed by linear interpolation. Figure 8 shows the three-dimensional deformation model of Sentinel-1A.

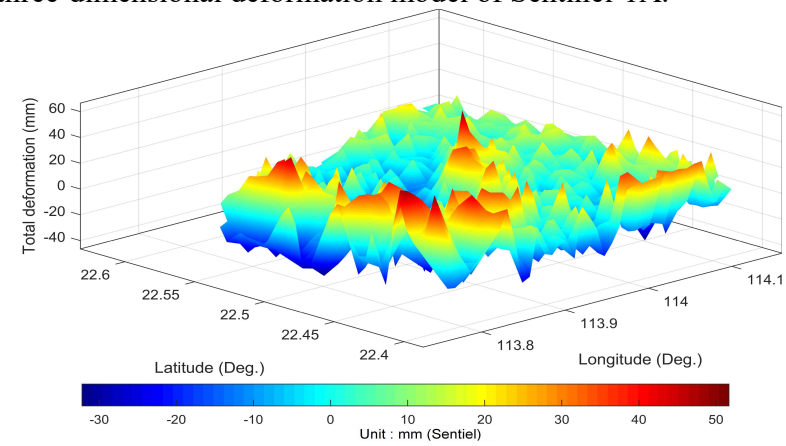

Figure 8. 3D deformation model of sentinel-1A

Overall, the two models show that from 2007 to 2010, the maximum cumulative subsidence of the reclamation area reached $-89.17 \mathrm{~mm}$, but the overall deformation trend of the land is relatively balanced, and this indicates that large subsidence only occur in some small areas. However, by 2017 2019, there was a large subsidence on the west coast of Shenzhen, and the largest cumulative subsidence reached $-41.30 \mathrm{~mm}$. In addition, the deformation model of 2017-2019 shows that the land subsidence in the Shenzhen reclamation area is very obvious.

The P2 region is intercepted from Fig. 5, and the Kriging interpolation is performed using the deformation point target to generate a subsidence model, as shown in Fig. 9. From Fig. 9, it can be found that two more obvious subsidence areas S1 and S2 are distributed on both sides of the Nanshan Mountain, and the remaining areas have less subsidence distribution. Due to space limitations, this paper only analyzed the settlement of the S1 and $\mathrm{S} 2$ regions.

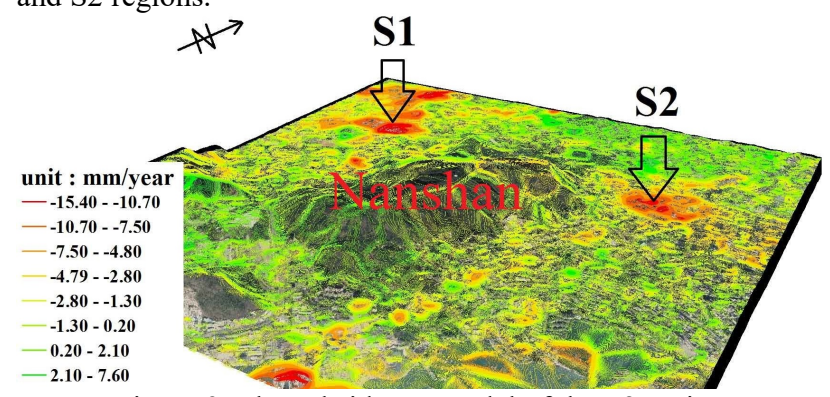

Figure 9. The subsidence model of the $\mathrm{P} 2$ region

Figure 10 shows a three-dimensional deformation map of the enlarged S1 and S2 regions. The point targets of the cd and ef sections are extracted from Fig. 10, and the cumulative deformation side view shown in Fig. 11 is generated. It can be seen from Figure 11 that in the observation time of this article (August 15, 2017 to March 14, 2019), the S1 and S2 areas are under construction. The construction and construction projects in the S1 area mainly include the construction of the land industrial plant area, the construction of commercial and residential buildings, and the construction of the subway project (the south extension line of Line 5 is under construction). The S2 area is mainly for commercial and residential construction. The increase in the land construction load brought about by the land works in the S1 area, and the excessive concentration of personnel activities may be the main cause of the subsidence of the area. In addition, the S1 area is constructing the south extension line of Line 5. In the process of subway construction, groundwater will be evacuated. Groundwater is the key to maintaining land balance, and excessive pumping will accelerate and expand land subsidence. The S2 area is mainly land engineering. Therefore, the subsidence of the S2 area may 
be caused by an increase in land construction load and selfconsolidation of the soil.
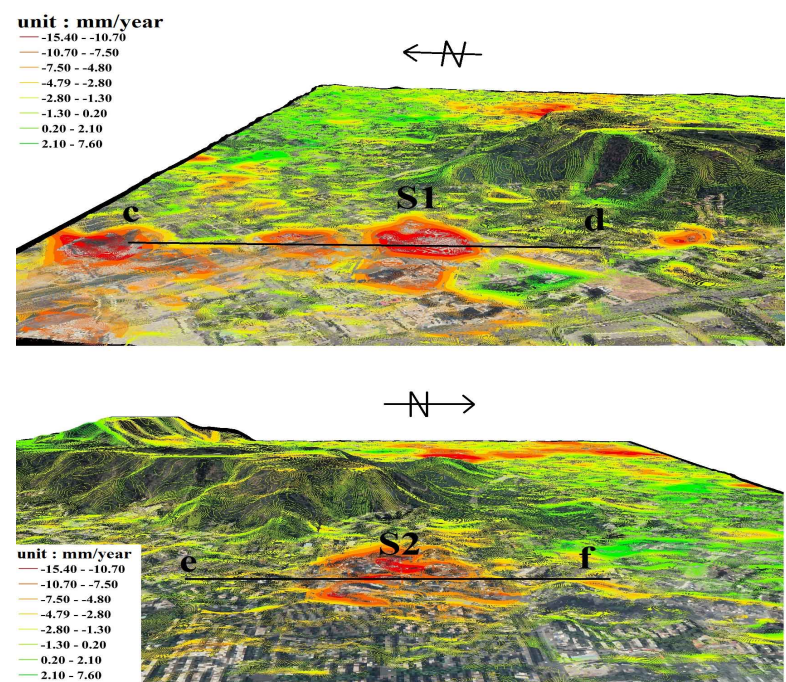

Figure 10. 3D deformation map of the $\mathrm{S} 1$ and $\mathrm{S} 2$ regions
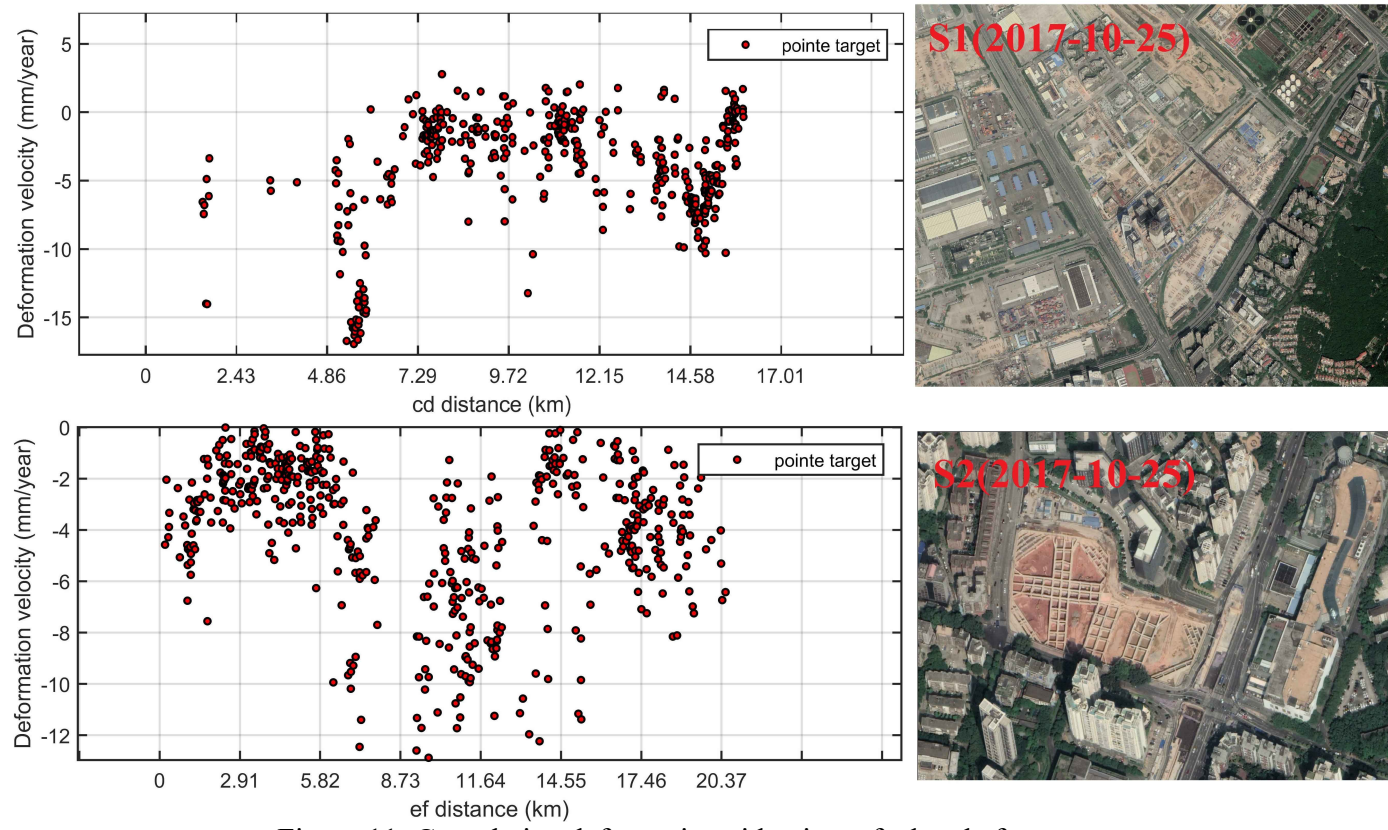

Figure 11. Cumulative deformation side view of cd and ef segments

Figure 12 shows an overview of the sedimentary layer distribution in the $\mathrm{P} 2$ region. From the perspective of time and space evolution, most of the P2 area is an alluvial plain, and Quaternary marine sediments are widely distributed in lowlying coastal land areas. Because the Quaternary marine sediments are widely distributed on the west coast of Shenzhen, the sediments in the west coast of Shenzhen have high water content, high compressibility, large porosity and weak shear strength. Among them, the thickness of the sediment is usually 3-10 meters, but it is 20 meters in some specific areas. Due to the high compressibility and low permeability of the alluvial clay, the soil is prone to land deformation during construction and self-consolidation. In addition, the P2 area has more silt around the reclamation area, and the source of the formation filler is complex, and the soil tends to be outwardly squeezed during the self-consolidation process. Coupled with the erosion of seawater by coastal areas, the water content of the land is increasing, the $\mathrm{P} 2$ area is prone to land subsidence.

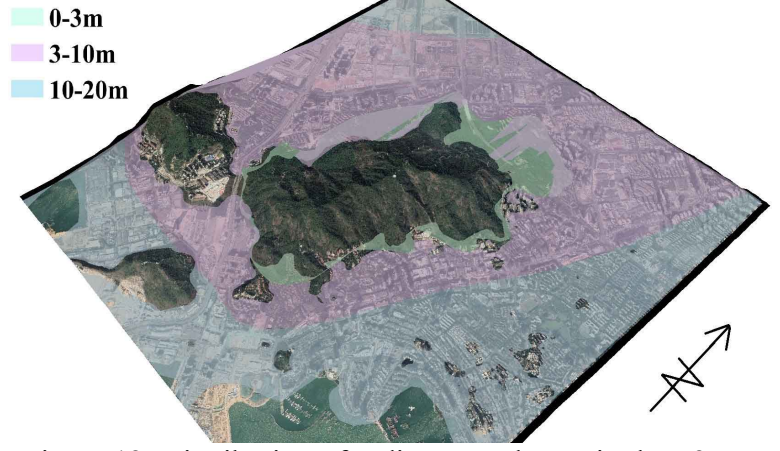

Figure 12. Distribution of sedimentary layers in the P2 area

\section{CONCLUSION}

This study used the TS-InSAR technology and the ENVISAT ASAR dataset obtained between 2007 and 2010 and the Sentinel-1A dataset from 2017 to 2019 to determine the 
subsidence in the Shenzhen reclamation area. We used ASTER GDEM V2 to remove the phase jump caused by spectral decorrelation between bursts. Based on the land subsidence time series of the reclamation area, a three-dimensional subsidence model of the reclamation area was established. By comparing and analyzing the subsidence results of two sets of satellite time series in the reclamation area, the temporal and spatial evolution of land subsidence and the cause of land subsidence in the reclamation area were analyzed. The results show that the test results of time series ENVISAT ASAR and Sentinel-1A have good continuity in subsidence spatialtemporal variation: From 2007 to 2010, the land subsidence in most areas of Shenzhen reclamation area is relatively stable, and subsidence area is mainly distributed in Baoan District, the maximum subsidence rate in Baoan District is $-23.12 \mathrm{~mm} /$ year. From 2017 to 2019, land subsidence in the reclamation area showed a tendency to spread from west to east. The subsidence characteristics of Nanshan District are the most obvious, and the maximum subsidence rate is $-17.52 \mathrm{~mm} /$ year. Through time series analysis, it is found that the transfer of Shenzhen's economic construction is likely to be the main reason for the spread of land subsidence in the reclamation area. Because of the rapid development of Shenzhen's economy and the concentration of personnel, the land subsidence in the reclamation area of Shenzhen is becoming more and more obvious. In addition, the fragile geological environment of the reclamation area may also cause land subsidence.

\section{ACKNOWLEDGEMENTS}

This work was supported by the National Natural Science Foundation of China (Grant Nos.41461089 and 41604019); the Guangxi Natural Science Foundation Project (Grant No. 2018GXNSFBA050006); the Key Laboratory of Geospace Environment and Geodesy, Ministry of Education, Wuhan University (Grant No. 18-01-01); the Guangxi Science and Technology Plan Project (Grant No. GUIKE AD19110107); the Wuhan Science and Technology Plan Project (Grant No. 2019010702011314); the Foundation of Guilin University of Technology (Grant No. GUTQDJJ2018036); the Guangxi Young and Middle-aged Teacher Basic Ability Improvement Project (Grant No. 2018KY0247); the Guangxi Spatial Information Key Laboratory of Surveying and Mapping (Grant Nos. 16-380-25-22 and 15-140-07-34).

\section{REFERENCES}

Chen, G., Zhang, Y., Zeng, R., Yang, Z., Chen, X., Zhao, F., Meng, X., 2018. Detection of land subsidence associated with land creation and rapid urbanization in the chinese loess plateau using time series insar: A case study of Lanzhou new district. Remote Sensing, 10(2), 270-292.

Du, Y., Feng, G., Li, Z., Peng, X., Zhu, J., Ren, Z., 2017. Effects of external digital elevation model inaccuracy on StaMPS-PS processing: a case study in Shenzhen, China. Remote Sensing, 9(11), 1115-1133.

Du, Y., Feng, G., Li, Z., Peng, X., Zhu, J., Ren, Z., 2017. Effects of external digital elevation model inaccuracy on StaMPS-PS processing: a case study in Shenzhen, China. Remote Sensing, 9(11), 1115-1140.

Guo, J., Zhou, L., Yao, C., Hu, J., 2016. Surface subsidence analysis by multi-temporal insar and grace: A case study in Beijing. Sensors, 16(9), 1495-1512.
Shi, Y., Tang, Y., Lu, Z., Kim, J. W., Peng, J., 2019. Subsidence of sinkholes in Wink, Texas from 2007 to 2011 detected by time-series InSAR analysis. Geomatics, Natural Hazards and Risk, 10(1), 1125-1138.

Tang, W., Yuan, P., Liao, M., Balz, T., 2018. Investigation of Ground Deformation in Taiyuan Basin, China from 2003 to 2010, with Atmosphere-Corrected Time Series InSAR. Remote Sensing, 10(9), 1499-1520.

Wang, J., Yu, W., Deng, Y., Wang, R., Wang, Y., Zhang, H., Zheng, M., 2019. Demonstration of Time-Series InSAR Processing in Beijing Using a Small Stack of Gaofen-3 Differential Interferograms. Journal of Sensors, 2019.

Wang, T., DeGrandpre, K., Lu, Z., Freymueller, J. T., 2018. Complex surface deformation of Akutan volcano, Alaska revealed from InSAR time series. International Journal of Applied Earth Observation and Geoinformation, 64, 171-180.

Xu, B., Feng, G., Li, Z., Wang, Q., Wang, C., Xie, R., 2016. Coastal subsidence monitoring associated with land reclamation using the point target based SBAS-InSAR method: A case study of Shenzhen, China. Remote Sensing, 8(8), 652-673.

Zhou, L., Guo, J., Hu, J., Ma, J., Wei, F., Xue, X., 2018. Subsidence analysis of ELH Bridge through ground-based interferometric radar during the crossing of a subway shield tunnel underneath the bridge. International Journal of Remote Sensing, 39(6), 1911-1928.

Zhou, L., Guo, J., Hu, J., Li, J., Xu, Y., Pan, Y., Shi, M., 2017. Wuhan surface subsidence analysis in 2015-2016 based on sentinel-1a data by SBAS-InSAR. Remote Sensing, 9(10), 9821002 .

Zhang, Z., Wang, C., Wang, M., Wang, Z., Zhang, H., 2018. Surface deformation monitoring in Zhengzhou city from 2014 to 2016 using time-series insar. Remote Sensing, 10(11), 17311747.

Zhang, X., Zhang, H., Wang, C., Zhang, B., Wu, F., Wang, J., Zhang, Z., 2019. Time-Series InSAR Monitoring of Permafrost Freeze-Thaw Seasonal Displacement over Qinghai-Tibetan Plateau Using Sentinel-1 Data. Remote Sensing, 11(9), 10001018. 